\title{
Evaluasi Kesesuaian Lahan untuk Tanaman Kakao Berbasis Sistem Informasi Geografis di Kecamatan Nan Sabaris Kabupaten Padang Pariaman
}

\author{
Widya Oktavia', Siswandana ${ }^{2}$ \\ 1STKIP Ahlussunnah Bukittinggi \\ JI Diponegoro N0.8 Kec Guguk Panjang, Kota Bukittinggi, Sumatera Barat \\ 2STKIP Ahlussunnah Bukittinggi \\ JI Diponegoro N0.8 Kec Guguk Panjang, Kota Bukittinggi, Sumatera Barat \\ Email corresponding: widyaoktavia85@gmail.com
}

\begin{abstract}
The purpose of this study is to analyze and determination: level of land suitability, spatial distribution of land suitability and directive of land arrangement for cocoa plants-based SIG in Padang Pariaman District at Nan Sabaris Sub-District. The technique of determining sample points is based on land units with a purposive sampling method. Analysis of the data used is the comparison of matching between land characteristics with class criteria of land suitability. As a results showed that : 1) The level of land suitability for cocoa planting area in Nan Sabaris subdistrict can be categorized into 2 (two) land suitability levels, i.e. very suitable area of $1197.4 \mathrm{Ha}$ with land units Qh.I.F1.Ldg. Gh and in accordance with an area of 2252.3 Ha with land units: Qh.I.F1.Swh.Reg, Qh.I.M5.Swh.Reg, Qh.I.F1.Swh.Gh, Qh.I.F1.Pmk.Reg, Qh.I.M5.Pmk.Reg, Qh.I.D1.Pmk.Gh, Qh.I.F1.Pmk.Gh, Qh.I.F1.Ldg.Reg, Qh.I.M5.Ldg.Reg, Qh.I.D1.Ldg.Gh. 2) Spatial distribution of land that is very suitable is the land unit in the village of Pauh Kamba. Whereas the appropriate categories are Nagari Sunua, Sunua tengah, Kuraitaji, Kaplokoto, Paguah dalam. 3) Directive of land arrangement in Nan Sabaris sub-district, all land units are suitable for cacao plants.
\end{abstract}

Keywords: Suitability of land, Cocoa, Geography Information System

\begin{abstract}
Abstrak
Penelitian ini bertujuan untuk mengetahui dan menganalisis tentang : tingkat kesesuaian lahan, sebaran spasial kesesuaian lahan dan arahan penataan lahan untuk tanaman kakao berbasis SIG di Kecamatan Nan Sabaris Kabupaten Padang Pariaman. Penelitian ini dirancang dengan menggunakan metode survey. Teknik penentuan titik sampel berdasarkan satuan lahan dengan metode sampel purposif. Analisis data yang digunakan adalah pembandingan matching antara karakteristik lahan dengan kriteria kelas kesesuaian lahan. Hasil penelitian menunjukkan bahwa : 1). Tingkat kesesuaian lahan untuk areal penanaman kakao di Kecamatan Nan Sabaris dapat dikategorikan atas 2 (dua) tingkat kesesuaian lahan, yakni Sangat Sesuai seluas 1197,4 Ha dengan satuan lahan Qh.I.F1.Ldg.Gh dan Sesuai dengan luas 2252,3 Ha dengan satuan lahan : Qh.I.F1.Swh.Reg, Qh.I.M5.Swh.Reg, Qh.I.F1.Swh.Gh, Qh.I.F1.Pmk.Reg, Qh.I.M5.Pmk.Reg, Qh.I.D1.Pmk.Gh, Qh.I.F1.Pmk.Gh, Qh.I.F1.Ldg.Reg, Qh.I.M5.Ldg.Reg, Qh.I.D1.Ldg.Gh. 2) Sebaran spasial lahan yang sangat sesuai adalah satuan lahan di Nagari Pauh Kamba. Sedangkan untuk kategori sesuai adalah Nagari Sunua, Sunua tengah, Kuraitaji, Kapalokoto, Paguah dalam. 3) Arahan penataan lahan di Kecamatan Nan Sabaris, semua satuan lahan cocok diperuntukan untuk tanaman kakao.
\end{abstract}

Kata Kunci : Kesesuaian lahan, Kakao, Sistem Informasi Geografi (SIG).

\section{PENDAHULUAN}

Perencanaan penggunaan lahan yang baik harus memperhatikan tingkat kemampuan dan kesesuaian sumber daya lahan. Rayes (2007) menjelaskan kesesuaian lahan adalah tingkat kecocokkan suatu bidang lahan untuk suatu penggunaan tertentu. Evaluasi lahan merupakan suatu proses menduga potensi sumber daya lahan untuk berbagai penggunaan. Hasil evaluasi lahan akan memberikan informasi dan arahan penggunaan lahan yang sesuai dengan keperluan (Ritung \& Wahyunto, 2007). 
Evaluasi lahan sangat bermanfaat dalam sektor pertanian dan perkebunan. Kontribusi sub sektor perkebunan dalam PDB yaitu sekitar 3,47 persen pada tahun 2017 merupakan urutan pertama disektor Pertanian, Peternakan, Perburuan, dan Jasa pertanian (Statistik, 2018). Pada sektor perkebunan, Indonesia merupakan negara terbesar ketiga setelah Ivory-Coast dan Ghana, yang nilai produksi kakao pada tahun 2010 sebesar 1.315.800 ton/thn (Karmawati \& Mahmud, 2010). Luas areal usaha tanaman kakao di Kabupaten Padang Pariaman adalah $12.772 \mathrm{Ha}$ dengan jumlah produksi adalah 5434,54 ton (Dinas Pertanian dan Ketahanan Pangan Padang Pariaman, 2018). Salah satu kecamatan yang mengembangkan kakao di Kabupaten Padang Pariaman adalah Kecamatan Nan Sabaris dengan luas $375 \mathrm{Ha}$ dengan hasil produksi 99,25 ton (Dinas Pertanian dan Ketahanan Pangan Padang Pariaman, 2018).

Peningkatan hasil produksi kakao ini sangat penting, karena peluangnya sangat besar, mengingat kebutuhan biji kakao dunia belum dapat terpenuhi sehingga wilayah- wilayah yang berpotensi untuk dilakukan budidaya kakao harus dikembangkan. Dari hasil tinjauan lapangan terlihat di daerah Kecamatan $\mathrm{Nan}$ Sabaris masih banyak lahan- lahan kosong yang berpotensi untuk ditanami kakao.

Berdasarkan latar belakang tersebut maka peneliti sangat tertarik untuk mengetahui apakah daerah Kabupaten Padang Pariaman khususnya Kecamatan Nan Sabaris cocok atau tidak dijadikan sebagai areal pertanian kakao. Di samping itu, peneliti ingin mengetahui bagaimana tingkat kesesuaian lahan untuk tanaman kakao, dan mengkaji kebijakan penataan lahan yang diperuntukkan untuk tanaman kakao yang ada di Kabupaten Padang Pariaman.

\section{METODOLOGI PENELITIAN}

Penelitian ini dirancang dengan menggunakan metode survey. Sampel penelitian ditentukan dengan metode purposive sampling. Analisis data yang digunakan adalah pembandingan matching antara karakteristik lahan dengan kriteria kelas kesesuaian lahan.

Lokasi penelitian ini adalah seluruh lahan yang terdapat di Kecamatan Nan Sabaris Kabupaten Padang Pariaman. Waktu penelitian dimulai dari bulan Mei sampai Juli 2019.

Bahan yang digunakan dalam penelitian ini adalah : peta geologi, peta tanah, peta jenis lereng, peta penggunaan lahan, peta RTRW Kabupaten Padang Pariaman. Alat yang digunakan dalam penelitian ini : GPS, Abney level, pita ukur, cangkul, ring sampel dan lainlain.

\section{HASIL DAN PEMBAHASAN}

\section{Satuan Bentuk Lahan}

Berdasarkan hasil analasis peta, diperoleh 11 bentuk satuan lahan. Satuan lahan ini memiliki karaktristik yang berbeda antara satu dengan lainnya. Adapun satuan lahan tersebut sebagi berikut.

a. Satuan Bentuklahan Dataran Aluvial (F1), Kelas Lereng I Dengan Penggunaan Lahan Sawah (Qh.I.F1.Swh.Reg). Satuan lahan ini mempunyai topografi datar (0-8\%) yang dimanfaatkan untuk areal sawah dengan elevasi $3 \mathrm{~m}$ dpl, kedalaman efektif tanah 60$70 \mathrm{~cm}$, drainasenya lapisan bawah terdapat bercak, tekstur tanah liat berdebu, kadar $\mathrm{pH}$ 4,45, kandungan C-Organik 2,45\%, kadar nitrogen dalam tanah $0,06 \%$, kadar posfor $21,11 \%$, kadar kalium $10,33 \%$, KTK 12,58 $\mathrm{cmol} / \mathrm{kg}$, curah hujan $3.715,8 \mathrm{~mm} / \mathrm{th}$. Jumlah nilai harkat yang diperoleh adalah 34, tergolong pada kelas II (sesuai).

b. Satuan Bentuklahan Asal Marin (Tombolo) (M5), Kelas Lereng I Dengan Penggunaan Lahan Sawah (Qh.I.M5.Swh.Reg). Satuan lahan ini mempunyai topografi datar (0$8 \%$ ) yang dimanfaatkan untuk areal sawah dengan elevasi $3 \mathrm{~m}$ dpl, kedalaman efektif tanah 60-70 cm, drainasenya lapisan bawah terdapat bercak, tekstur tanah lempung liat berdebu, kadar $\mathrm{pH}$ 5,43 asam, kandungan C-Organik 1,62\%, kadar nitrogen dalam tanah $0,07 \%$, kadar posfor $43,71 \%$, kadar kalium $18,63 \%$, KTK $14,16 \mathrm{Cmol} / \mathrm{kg}$, curah hujan $3.715,8 \mathrm{~mm} / \mathrm{th}$. Jumlah nilai harkat yang diperoleh adalah 36 , tergolong pada kelas II (sesuai).

c. Satuan Bentuklahan Dataran Aluvial (F1), Kelas Lereng I Dengan Penggunaan Lahan Sawah (Qh.I.F1.Swh.Gh). Satuan lahan ini mempunyai topografi datar (0-8\%) yang dimanfaatkan untuk areal sawah dengan elevasi $4 \mathrm{~m}$ dpl, kedalaman efektif tanah 60$70 \mathrm{~cm}$, drainase lapisan bawah terdapat bercak, tekstur tanah lempung liat berpasir, kadar $\mathrm{pH}$ 4,83 asam, kandungan Corganik $3,95 \%$, kadar nitrogen dalam tanah $0,09 \%$, kadar posfor $38,54 \%$, kadar kalium $18,08 \%$, KTK $14,09 \mathrm{Cmol} / \mathrm{kg}$, curah hujan $3715,8 \mathrm{~mm} /$ th. Jumlah nilai harkat 
yang diperoleh adalah 36, tergolong pada kelas II (sesuai).

d. Satuan Bentuk Lahan Dataran Aluvial (F1), Kelas Lereng I dengan Penggunaan Lahan Pemukiman (Qh.I.F1.Pmk.Reg). Satuan lahan ini mempunyai topografi datar (O$8 \%$ yang dimanfaatkan untuk areal pemukiman dengan elevasi $3 \mathrm{~m} \mathrm{dpl}$, kedalaman efektif tanah 100-110 cm, drainasenya warna seragam lapisan bawah terdapat bercak, tekstur tanah lempung berdebu, kadar $\mathrm{pH}$ 5,91 asam, kandungan bahan c-organik 2,97\%, kadar nitrogen dalam tanah 0,09\%, kadar posfor 38,54\%, kadar kalium 44,76\%, KTK 12,38 Cmol/kg, curah hujan $3715,8 \mathrm{~mm} / \mathrm{th}$. Jumlah nilai harkat yang diperoleh adalah 39 , tergolong pada kelas II ( sesuai).

e. Satuan Bentuklahan Asal Marin (Tombolo) (M5), Kelas Lereng I Dengan Penggunaan Lahan Ladang, Kebun campuran (Qh.I.M5.Pmk.Reg). Satuan lahan ini mempunyai topografi datar (0-8\%) yang penggunaan lahannya pemukiman dengan elevasi $4 \mathrm{~m}$ dpl, kedalaman efektif tanah > $150 \mathrm{~cm}$, drainasenya warna seragam dan tidak terdapat bercak, tekstur tanah lempung berpasir, kadar $\mathrm{pH}$ 5,24 asam, kandungan bahan C-organik 3,92\%, kadar nitrogen dalam tanah 0,09\%, kadar posfor $35,03 \%$, kadar kalium 3,85\%, KTK 8,71 $\mathrm{Cmol} / \mathrm{kg}$, curah hujan $3715,8 \mathrm{~mm} / \mathrm{th}$. Jumlah nilai harkat yang diperoleh adalah 40 , tergolong kelas II (sesuai).

f. Satuan Bentuklahan Asal Denudasional, Perbukitan Terkikis (D1) Kelas Lereng I dengan Penggunaan Lahan Pemukiman (Qh.I.D1.Pmk.Gh). Satuan lahan ini mempunyai topografi datar (0-8\%) yang penggunaan lahannya pemukiman dengan elevasi $5 \mathrm{~m}$ dpl, kedalaman efektif tanah 100-110 cm, drainasenya warna seragam lapisan bawah tidak terdapat bercak, tekstur tanah liat berdebu, kadar $\mathrm{pH} \mathrm{5,31} \mathrm{asam,}$ kandungan bahan C-organik 1,90\%, kadar nitrogen dalam tanah 0,07\%, kadar posfor $7,66 \%$, kadar kalium 18,27\%, KTK $17,33 \mathrm{Cmol} / \mathrm{kg}$, curah hujan $3715,8 \mathrm{~mm} / \mathrm{th}$. Jumlah nilai harkat yang diperoleh adalah 36 , tergolong kelas II (sesuai).

g. Satuan Bentuklahan Dataran Aluvial (F1), Dengan Kelas Lereng I Dengan Penggunaan Lahan Pemukiman (Qh.I.F1.Pmk.Gh). Satuan lahan ini mempunyai topografi datar (0-8\%) yang penggunaan lahannya pemukiman dengan elevasi $3 \mathrm{~m} \mathrm{dpl}$, kedalaman efektif tanah $>150 \mathrm{~cm}$, drainasenya warna seragam, lapisan tidak terdapat bercak, tekstur lempung liat berdebu, kadar $\mathrm{pH} 4,05$ asam, kandungan bahan c-organik 1,85\%, kadar nitrogen dalam tanah $0,07 \%$, kadar posfor $6,13 \%$, kadar kalium $17,12 \%$, KTK $12,45 \mathrm{Cmol} / \mathrm{kg}$, curah hujan $3715,8 \mathrm{~mm} / \mathrm{th}$. Jumlah nilai harkat yang diperoleh adalah 37, tergolong pada kelas II (sesuai).

h. Satuan Bentuklahan Dataran Aluvial (F1), Kelas Lereng I Dengan Penggunaan Lahan Kebun Campuran (Qh.I.F1.Kc.Reg). Satuan lahan ini mempunyai topografi datar (0$8 \%$ ) yang penggunaan lahannya kebun campuran, dengan elevasi $3 \mathrm{~m} \mathrm{dpl}$, kedalaman efektif tanah 100-110 cm, drainasenya lapisan bawah tidak terdapat bercak, tekstur lempung liat berdebu, kadar $\mathrm{pH}$ 5,55 asam, kandungan bahan c-organik 2,95\%, kadar nitrogen dalam tanah 0,09\%, kadar posfor $179,98 \%$, kadar kalium $4,01 \%$, KTK $14,35 \mathrm{Cmol} / \mathrm{kg}$, curah hujan 3715,8 $\mathrm{mm} / \mathrm{th}$. Jumlah nilai harkat yang diperoleh adalah 39, tergolong pada kelas II (sesuai).

i. Satuan Bentuklahan Asal Marin (Tombolo) (M5), Kelas Lereng I Dengan Penggunaan Kebun Campuran (Qh.I.M5.Kc.Reg). Satuan lahan ini mempunyai topografi datar (0$8 \%$ yang penggunaan lahannya kebun campuran dengan elevasi $4 \mathrm{~m} \mathrm{dpl}$, kedalaman efektif tanah 120-130 cm, drainasenya warna seragam lapisan bawah tidak terdapat bercak, tekstur pasir berlempung, kadar pH 4,81 asam, kandungan bahan c- organik 2,87\%, kadar nitrogen dalam tanah 0,09\%, kadar posfor $22,33 \%$, kadar kalium 16,46\%, KTK $12,78 \mathrm{Cmol} / \mathrm{kg}$, curah hujan $3715,8 \mathrm{~mm} / \mathrm{th}$. Jumlah nilai harkat yang diperoleh adalah 36 , tergolong pada kelas II (sesuai).

j. Satuan Bentuklahan Asal Denudasional, Perbukitan Terkikis (D1) Kelas Lereng I Dengan Penggunaan Lahan Kebun Campuran (Qh.I.D1.Kc.Gh). Satuan lahan ini mempunyai topografi datar (0-8\%) yang penggunaan lahannya kebun campuran dengan elevasi $5 \mathrm{~m}$ dpl, kedalaman efektif tanah > $150 \mathrm{~cm}$, drainasenya warna seragam lapisan bawah tidak terdapat bercak, tekstur liat berdebu, kadar pH 5,62 asam, kandungan bahan c- organik 2,40\%, kadar nitrogen dalam tanah 0,07\%, kadar posfor $186,11 \%$, kadar kalium $55,47 \%$, KTK $20,59 \mathrm{Cmol} / \mathrm{kg}$, curah hujan $3715,8 \mathrm{~mm} / \mathrm{th}$. 
Jumlah nilai harkat yang diperoleh adalah 41, tergolong pada kelas II (sesuai).

k. Satuan Bentuklahan Dataran Aluvial (F1), Kelas Lereng I Dengan Penggunaan Lahan Kebun Campuran (Qh.I.F1.Kc.Reg). Satuan lahan ini mempunyai topografi datar (0$8 \%$ yang penggunaan lahannya kebun campuran dengan elevasi $4 \mathrm{~m}$ dpl, kedalaman efektif tanah $>150 \mathrm{~cm}$, drainasenya warna seragam lapisan bawah tidak terdapat bercak, tekstur liat berdebu, kadar $\mathrm{pH}$ 5,49 asam, kandungan bahan corganik $6,57 \%$, kadar nitrogen dalam tanah 0,13\%, kadar posfor 90,21\%, kadar kalium $36,53 \%$, KTK $18,55 \mathrm{Cmol} / \mathrm{kg}$, curah hujan $3715,8 \mathrm{~mm} / \mathrm{th}$. Jumlah nilai harkat yang diperoleh adalah 42, tergolong pada kelas I (sesuai).

\section{Sebaran Spasial Kesesuaian Lahan Untuk Tanaman Kakao di Daerah Penelitian.}

Adapun satuanlahan dan lokasi yang kriteria Sangat Sesuai terdapat di Nagari Pauh kamba dan Sesuai untuk tanaman kakao di nagari: Sunua, Sunua tengah, Kuraitaji, Kapaolo koto, Paguah dalam. Untuk lebih jelasnya dapat dilihat pada gambar 1 dibawah ini:

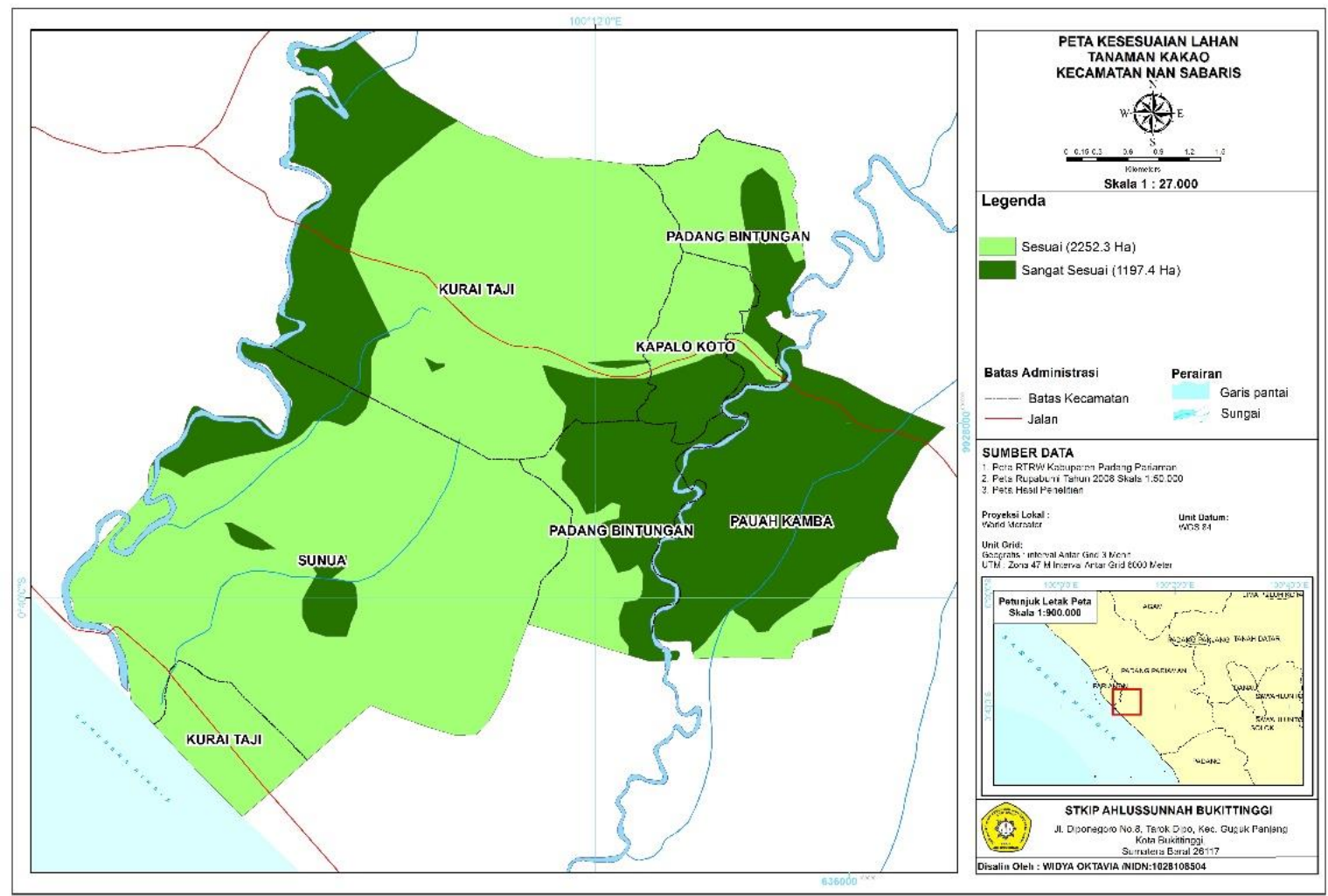

Gambar.1.Peta Kesesuaian Lahan Untuk Tanaman Kakao Kec. Nan Sabaris

\section{Arahan Penataan Lahan Untuk Tanaman kakao}

Hasil overlay peta kesesuaian lahan untuk tanaman kakao dengan peta RTRW Kabupaten Padang Pariaman maka diperoleh satu zona yaitu semua wilayah diperuntukkan untuk tanaman kakao adalah 3449,7 Ha. Arahan kebijakan penataan lahan untuk budidaya tanaman kakao dapat dilihat pada gambar dibawah: 


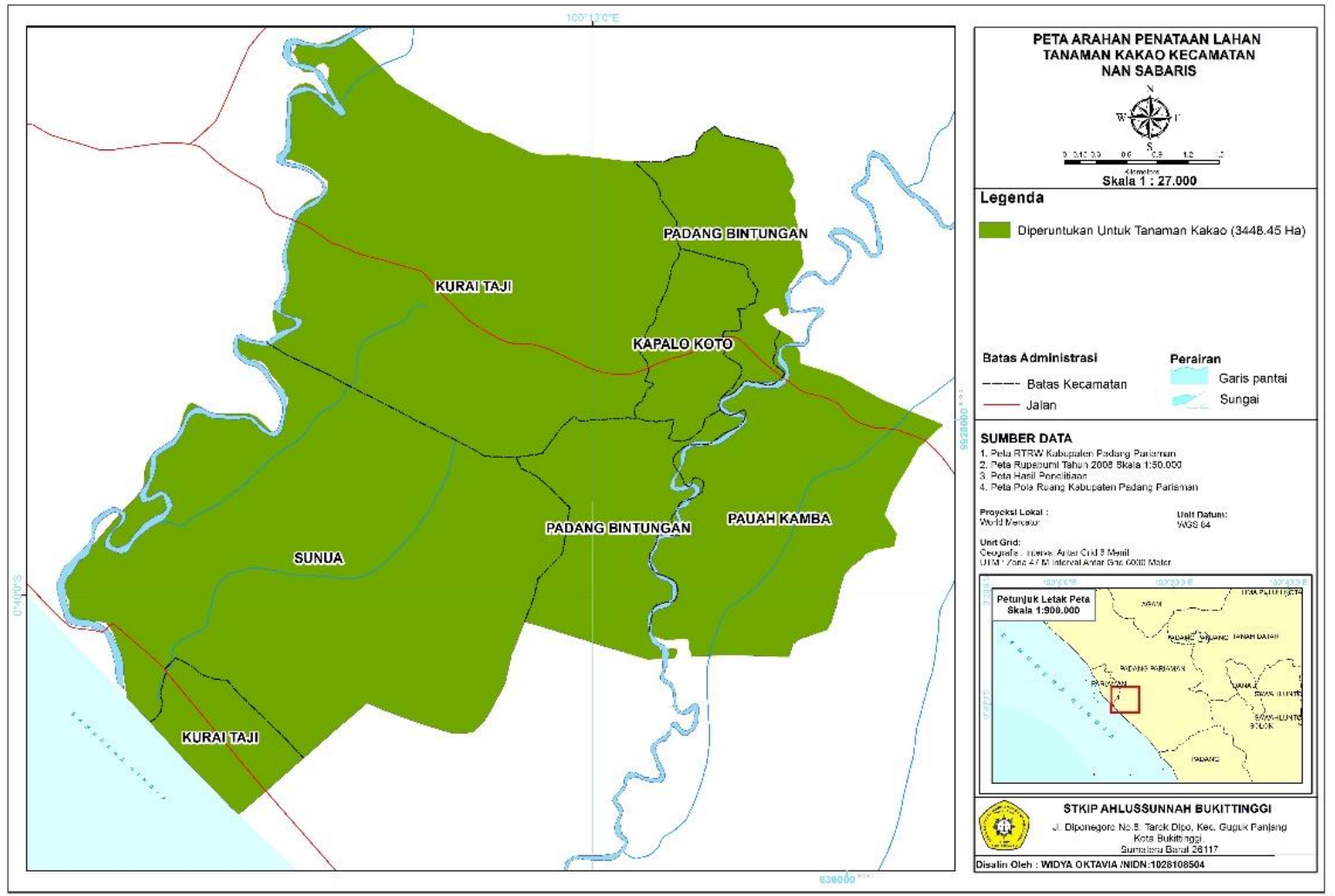

Gambar 2. Peta Arahan Penataan Lahan Tanaman Kakao Kec. Nan Sabaris

\section{Pembahasan}

Dari hasil identifikasi yang ada pada daerah penelitian, maka satuan lahan yang termasuk dalam kategori sangat sesuai dan sesuai mempunyai faktor pendukung dan penghambat yang berbeda. Faktor penghambat pada evaluasi kesesuaian lahan untuk tanaman kakao di Kecamatan Nan Sabaris salah satunya adalah unsur iklim dan cuaca yang berupa curah hujan. Curah hujan daerah penelitian yang terlalu besar tidak baik untuk tanaman kakao hal ini dapat menyebabkan busuk buah.

Hasil diatas sependapat dengan penelitian yang di lakukan oleh Fadholi \& Supriatin (2012) yang mengemukakan "Unsur iklim yang dianalisis adalah unsur curah hujan yang sangat berperan langsung terhadap pertumbuhan tanaman dibanding unsur-unsur iklim lainnya.

Prasetya \& Sunaryo (2013) menjelaskan penggunaan lahan memiliki hubungan yang erat dengan nilai lahan. Nilai lahan dapat dipengaruhi dari kesuburan dan lokasi lahan tersebut. Lahan yang subur dapat memberikan output yang lebih besar pula. Dari hasil evaluasi lahan yang dilakukan di Kecamatan Nan Sabaris diperoleh kelas lahan yang sangat sesuai adalah Nagari Pauh Kamba. Nagari Pauh Kamba merupakan bagian dari Kecematan Nan Sabaris menghasilkan output yang besar jika dibandingkan dengan nagari lainya yaitu dengan jumlah petani 160 orang jumlah batang kakao 6004 batang. Untuk itu perlu ditingkatkan lagi pengembangan budidaya kakao di Kecamatan Nan Sabaris mengingat masih ada lahan yang belum dimanfaatkan.

Peta kesesuaian lahan untuk tanaman kakao di daerah penelitian terlihat bahwa sebaran spasial untuk karakteristik lahan dengan ordo sesuai dan kelas sangat sesuai tersebar di beberapa nagari yang ada Kecamatan Nan Sabaris. Sehinga dapat dimanfaatkan sebagai sumber informasi khususnya informasi pertanian kakao. Dari hasil overlay peta kesesuaian lahan untuk tanaman kakao dengan peta RTRW Kabupaten Padang Pariaman maka diperoleh peta arahan penataan lahan yaitu semua nagari cocok untuk peruntukan tanaman kakao. Hal ini disebabkan kelas lereng daerah ini mencukupi sebagai syarat hidup kakao dan daerah ini tidak berada pada kawasan hutan lindung dan suaka alam.

Hasil diatas sesuai dengan pendapat Malinggreau dan Rosalia dalam Syukur (2008) mengemukakan "Suatu unit penggunaan lahan mewakili tidak lebih suatu mental construct yang di desain untuk memudahkan inventarisasi dan aktivitas pemetaan identifikasi pemantauan dan elevasi penggunaan lahan perlu selalu dilakukan pada setiap periode tertentu. Penggunaan lahan menjadi bagian yang penting dalam usaha melakukan perencanaan dan pertimbangan dalam merumuskan kebijakan keruangan disuatu 
wilayah. Dengan adanya peta kesesuaian lahan dan peta arahan yang diperuntukkan untuk budidaya tanaman kakao diharapkan dapat memberikan informasi dalam pengembangan budidaya kakao sehingga hasil yang diharapkan juga dapat optimal.

\section{KESIMPULAN}

Tingkat kesesuaian lahan untuk areal penanaman kakao di Kecamatan Nan Sabaris dapat dikategorikan atas 2 (dua) tingkat kesesuaian lahan, yakni Sangat Sesuai dengan luas 1197,4 Ha dan Sesuai dengan luas 2252,3 Ha. Sebaran spasial lahan yang sangat sesuai terdapat di nagari Pauh kamba. Sedangkan yang sesuai adalah : terdapat di Nagari Sunua, Nagari Sunua Tengah, Kuraitadji, Kapalokoto dan Paguah dalam. Arahan Penataan Lahan untuk kakao, diperoleh satu kelas yaitu semua daerah penelitian cocok diperuntukan untuk tanaman kakao.

\section{UCAPAN TERIMAKASIH}

Penulis mengucapkan terima kasih kepada Direktorat Riset dan Pengabdian Masyarakat yang telah membiayai penelitian ini.

\section{DAFTAR PUSTAKA}

Dinas Pertanian dan Ketahanan Pangan Padang Pariaman. (2018). Laporan Tahunan Dinas Pertanian dan Kehutanan Pangan Kabupaten Padang Pariaman. Kabupaten Padang

\section{Pariaman.}

Fadholi, A., \& Supriatin, D. (2012). Sistem Pola Tanam Di Wilayah Priangan Berdasakan Klasifikasi Iklim Oldeman. Jurnal Geografi Gea, 12(2).

Karmawati, E., \& Mahmud, Z. (2010). Budidaya dan Pasca Panen Kakao. Pusat Penelitian Dan Pengembangan Perkebunan, Bogor.

Prasetya, N. A., \& Sunaryo, P. M. B. (2013). Faktor-faktor yang Mempengaruhi Harga Lahan di Kawasan Banjarsari Kelurahan Tembalang, Semarang. Teknik PWK (Perencanaan Wilayah Kota), 2(2), 223232.

Rayes, M. L. (2007). Metode inventarisasi sumber daya lahan. Andi. Yogyakarta.

Ritung, S., \& Wahyunto, F. A. (2007). H. Hidayat. Panduan Evaluasi Kesesuaian Lahan.

Statistik, B. P. (2018). Statistik Kakao Indonesia 2017. Jakarta (ID): Badan Pusat Statistik.

Syukur, S. (2008). ANALISIS KESESUAIAN LAHAN DI KEC. WITA PONDA DAN BUMI RAYA KAB. MOROWALI UNTUK PENGEMBANGAN PERKEBUNAN KELAPA SAWIT. Agroland: Jurnal IImu-llmu Pertanian, 15(1). 